\title{
Automated tracking of lava lake level using thermal images at Killauea Volcano, Hawai'i
}

\author{
Matthew R. Patrick*, Donald Swanson and Tim Orr
}

\begin{abstract}
Tracking the level of the lava lake in Halema'uma'u Crater, at the summit of Killauea Volcano, Hawai'i, is an essential part of monitoring the ongoing eruption and forecasting potentially hazardous changes in activity. We describe a simple automated image processing routine that analyzes continuously-acquired thermal images of the lava lake and measures lava level. The method uses three image segmentation approaches, based on edge detection, short-term change analysis, and composite temperature thresholding, to identify and track the lake margin in the images. These relative measurements from the images are periodically calibrated with laser rangefinder measurements to produce real-time estimates of lake elevation. Continuous, automated tracking of the lava level has been an important tool used by the U.S. Geological Survey's Hawaiian Volcano Observatory since 2012 in real-time operational monitoring of the volcano and its hazard potential.
\end{abstract}

Keywords: Kilauea, Lava lake, Thermal camera, Image processing, Volcano monitoring

\section{Introduction}

The current summit eruption at Kilauea Volcano began in March 2008 (Wilson et al. 2008; Patrick et al. 2013). It includes an active lava lake within the Overlook crater, which is within the larger Halema'uma'u Crater (Patrick et al. 2013; Orr et al. 2013) (Fig. 1). The lake experiences frequent changes in lava level (Patrick et al. 2013, 2014, 2015). On a day-to-day basis this change is on the order of $10-20 \mathrm{~m}$ but can be greater $(>100 \mathrm{~m})$ during eruptive events on the East Rift Zone (Orr et al. 2015; Patrick et al. 2015). Tracking the lava level in Halema'uma'u is an essential part of monitoring Kilauea's activity, and complements datasets such as gas emission, seismicity and ground deformation. The importance of summit lava level extends beyond the summit region, as higher summit lava levels reflect increased pressure in the overall magmatic system within Kilauea Volcano, and unusually high summit lava levels have preceded intrusions and/or the outbreak of new eruptive vents on Kïlauea's rift zones (Rowland and Munro 1993; Patrick et al. 2014, 2015; Orr et al. 2015). Monitoring summit lava level is another important tool for

\footnotetext{
* Correspondence: mpatrick@usgs.gov

Hawaiian Volcano Observatory-U.S. Geological Survey, PO Box 51, Hawai'i National Park, HI 96718, USA
}

judging the likelihood of potentially hazardous rift zone eruptive activity.

Thermal cameras at Halema'uma'u have proven effective for continuous monitoring of the lava lake because thermal imagery can "see" through thick volcanic fume in the Overlook crater which often obscures the view of the lake to normal webcams and the naked eye (Patrick et al. 2014). In this paper we present a simple image processing routine that performs customized analysis of incoming thermal images of the lava lake, producing automated measurements of lava level. This function runs in realtime in an operational volcano-monitoring environment at the Hawaiian Volcano Observatory (HVO) and aids in tracking activity levels at the summit vent.

\section{Methods}

The image processing techniques we present are applied to images from a stationary, continuously operating thermal camera on the Halema'uma'u Crater rim (Patrick et al. 2014). The camera is a Mikron Infrared (now Lumasense Technologies) M7500 8-14 micron camera using a lens with a horizontal field of view of $53^{\circ}$, operating at about $85 \mathrm{~m}$ above the Overlook crater rim (and typically 120-200 $\mathrm{m}$ line-of-sight distance from the lava lake surface). Images are $320 \times 240$ pixels in size. Although the images show calibrated temperatures

\section{Springer}




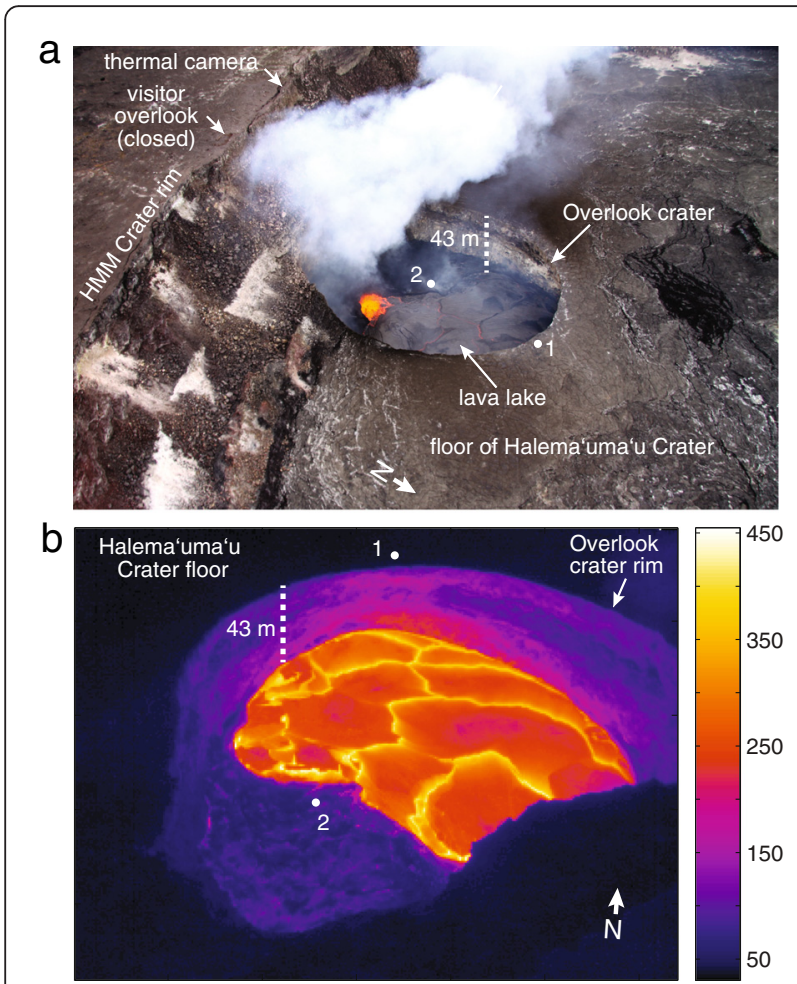

Fig. 1 Overview of the active lava lake in Halema'uma'u Crater, at the summit of Kilauea Volcano, Hawai'i. a. Aerial view looking southwest at the Overlook crater, which opened at the onset of eruptive activity in 2008 and is within Halema'uma'u Crater. In late 2012, the lava lake was about $160 \times 200 \mathrm{~m}$ in size, similar in size to the Overlook crater. Note position of thermal camera on the rim of Halema'uma'u Crater, denoted by "HMM crater rim". Image taken October 17, 2012, when the lava level was about $43 \mathrm{~m}$ below the Overlook crater rim. b. Example image from the thermal camera, taken within a few minutes of (a). Corresponding points between this image and (a) are shown by points 1 and 2. Temperature scale is degrees Celsius. The maximum measurable temperature of the thermal camera is $500{ }^{\circ} \mathrm{C}$

(Fig. 1b), fluctuating volcanic fume between the camera and lava surface may produce large errors in the apparent temperature values (Patrick et al. 2014). For our purposes, approximate temperatures are adequate. The maximum measureable temperature of this camera model is $500{ }^{\circ} \mathrm{C}$, which is adequate for monitoring the lava lake as the vast majority of the lake surface - consisting of large crustal plates - has apparent temperatures below that value.

Images are acquired every $5 \mathrm{~s}$ and transmitted to the observatory in real-time. Windows Scheduler runs the described function hourly, analyzing the preceding hour's images. We used Matlab version 2012b with the Image Processing toolbox. The function takes about $6 \mathrm{~min}$ on the computer that is also running the image acquisition (a dual-core $2.6 \mathrm{GHz}$ processor with $4 \mathrm{~Gb}$
RAM). This script to track lava level is one of a suite of Matlab scripts that comprise the thermal camera image acquisition scheme described by Patrick et al. (2014).

For each hour's worth of data (720 images), the function divides the images into two minute blocks (24 images). It applies three analyses to the images in each block and combines the results from these approaches to create a combined image that is used to isolate the lava lake and estimate lava level. Each 2 min block thus produces one estimate of lava level. Before the analyses are applied to the images, the function does a quality control check. If the maximum temperature in the image is below $300{ }^{\circ} \mathrm{C}$, then the lake is likely partly obscured by thick fog or rain. In this case, the lake is usually clearly visible, but the temperature contrast between the lake and crater walls has been muted, and therefore the function disregards the image.

1) Edge detection: The margin of the lava lake has an abrupt temperature boundary with the back wall of the crater (Fig. 2a), so an edge detection routine is effective at identifying the lake outline. The function applies Matlab's default edge detection function (Gonzalez et al. 2004) to each image in the two minute block. The script then builds a composite image (Patrick et al. 2010) of these individual edge detection images, in which the composite image shows the total extent of edge detection pixels through the two minute block, producing a binary image (Fig. 2b).

2) Maximum temperature thresholding: From each two minute block of data the function produces a single composite image of maximum temperature, which is constructed from the maximum value at each pixel position through that time span (Patrick et al. 2010). The composite image effectively shows the full spatial distribution of hot cracks on the lake surface during the time span, which provides higher contrast than a simple averaging of images. Simple thresholding at a high temperature $\left(300{ }^{\circ} \mathrm{C}\right)$ is then applied to this composite image, producing another binary image (Fig. 2c).

3) Temporal standard deviation: The dynamic nature of the lava-lake surface is another aspect that can be leveraged to distinguish it from the surrounding static crater walls. The standard deviation of temperature values at each pixel position through the two minute block is recorded, and used to construct a new "change" image. The lava-lake surface is constantly migrating, with hot incandescent cracks commonly passing through any given point on the lake surface. The temporal standard deviation is very high over the lake surface relative to the crater walls. The image of temporal standard deviation is thresholded at $40{ }^{\circ} \mathrm{C}$ to produce a third binary image (Fig. $2 \mathrm{~d}$ ). 

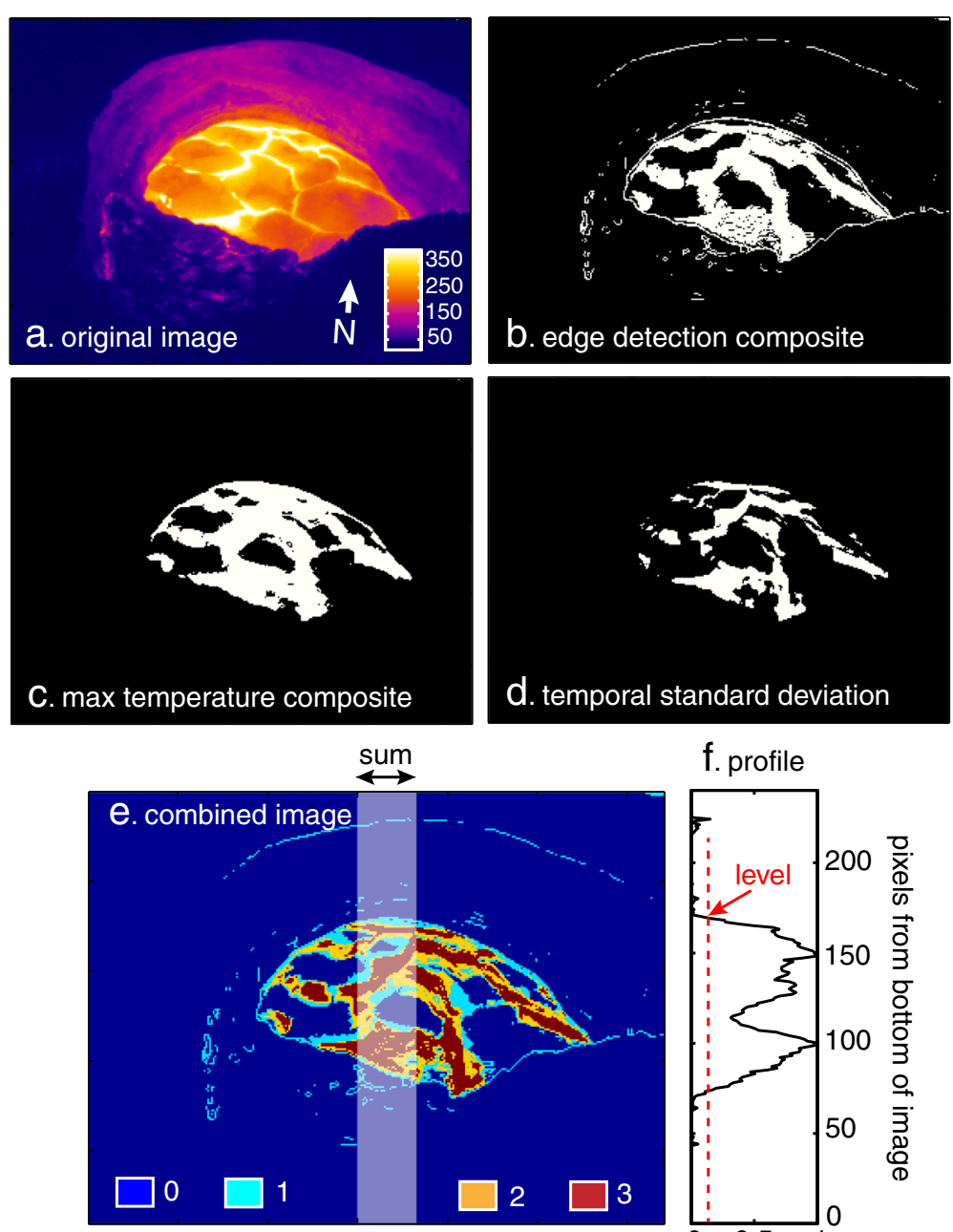

f. profile

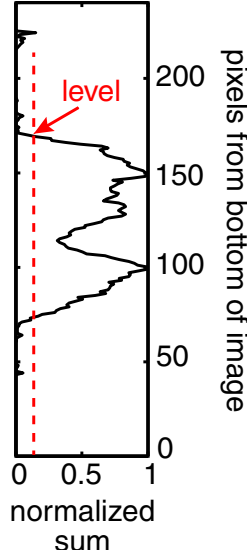

Fig. 2 Segmentation approaches for isolating the lava lake in the thermal images and measuring its level. Images taken November 23, 2012. a. One of the original images in two minute block of images used to construct the subsequent binary images in this figure. Image from November 23,2013 03:00 HST. b. Composite image generated from individual binary edge detection images from the 24 image block of data (two minutes). c. Composite image constructed by taking the maximum temperature at each pixel location within a 24 image block of data, and then thresholding at $300{ }^{\circ} \mathrm{C}$. d. Standard deviation calculated at each pixel through a two minute block of time, and thresholded at $40{ }^{\circ} \mathrm{C}$. e. Summed image from the three approaches, with colors denoting the sum (0-3) for each pixel. A pixel value of 3, for instance, indicates that all three binary images have a value of 1 at that location, while a pixel value of 0 indicates that none of the three images have a pixel value of 1 at that location. On the right side is the profile ( $\mathbf{f}$ ) constructed by summing pixels in each row in the swath of the image. An empirical threshold is then used to locate the boundary of the lake against the crater wall

\section{Combined image}

We combine the three binary images above to better isolate the lake from the remainder of the image, because the composited data are more consistently effective than any one criterion at detecting the lake surface owing to changing activity and shifting viewing conditions. The three binary images are summed to create a new composited image (Fig. 2e). A swath of image columns is extracted from the center of the combined image (Fig. 2f), which covers the northern margin of the lava lake. The pixel values in each row from this swath are summed to produce a single profile from the image. An empirical threshold is used to then distinguish the lava portion of this profile from the crater wall portion.

\section{Results}

Comparison with manual image measurements and laser rangefinder data

To judge the accuracy of the automated measurements we compared them to manual measurements of lava level from the same images over a time span of two months (April 5 to June 5, 2014) (Fig. 3a). Manual measurements were 

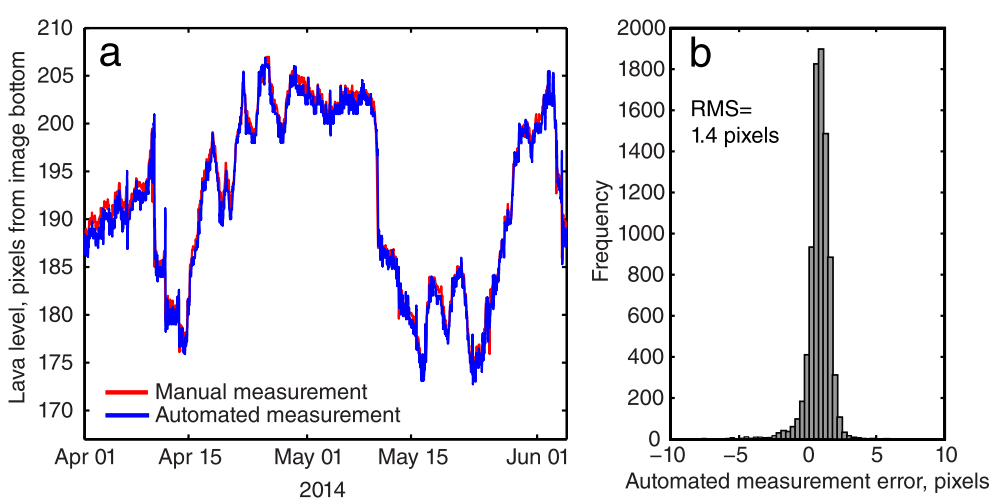

Fig. 3 Comparison of automated lava-level estimate (blue) with manual measurements (red). a. Lava level from April 1 to June 5, 2014. The measurements are done in terms of image pixels, and the hourly mean of the automated measurement is used here for comparison. The automated measurements are reasonably effective at following the actual lava level, with minor errors. b. Histogram of the difference between corresponding automated and manual measurements from the thermal images, calculated using one year of data (June 2013 to June 2014)

performed by identifying, by eye, the boundary of the lake and the far crater wall in a sequence of thermal images, and manually clicking on this boundary using the image analysis software Tracker (http://physlets.org/tracker/). Manual measurements are the most reliable, but they are time-consuming and impossible to implement in a realtime monitoring scheme. The lava level exhibited frequent fluctuations, with one notably abrupt drop on May 10, followed by a recovery in level by early June. The day-today changes in lava level measured by eye are represented well by the automated results, showing the same peaks and troughs. Occasional spikes in lava level are due to the appearance of transient spattering along the lava-lake margin. The script cannot discriminate between these spatter sources and genuine changes in lava level, but their appearance is so brief that it does not affect the overall usefulness of the script, which focuses on day-to-day, and longer timescale, changes.

The automated measurements of lava level in the images compare well with manual image measurements over longer periods as well. Over the course of a year (June 2013 to June 2014), we compared each hourly manual measurement with the automated measurement closest in time (Fig. 3b). The automated measurement error is less than or equal to one pixel (or roughly $1.1 \mathrm{~m}$ in elevation) $52 \%$ of the time, and less than or equal to two pixels (roughly $2.2 \mathrm{~m}$ ) $95 \%$ of the time. The overall RMS error is 1.4 pixels (roughly $1.5 \mathrm{~m}$ ).

The automated image measurements return lava level in units of pixels, producing a strictly relative measurement from the images. These pixel measurements, however, can be converted to absolute elevation values using daily laser rangefinder measurements of the lava level. Comparison with laser rangefinder data also serves as an absolute measure of how accurate the pixel measurements are for depicting the lava level elevation.
Corresponding data between January and May 2014 (Fig. 4) show a strong linear correlation $\left(R^{2}=0.98\right)$, in which one pixel of lava-lake level change in the thermal images equates to $1.1 \mathrm{~m}$ of change. Linear regression is used to convert the lava level in image pixels to absolute lava lake elevation.

\section{Operational routine}

The lava-level script runs once an hour and the resulting lava level (in image pixels) for the past hour is transferred automatically to VALVE (Cervelli et al. 2002), which is an internal $\mathrm{HVO}$ web application for viewing and comparing

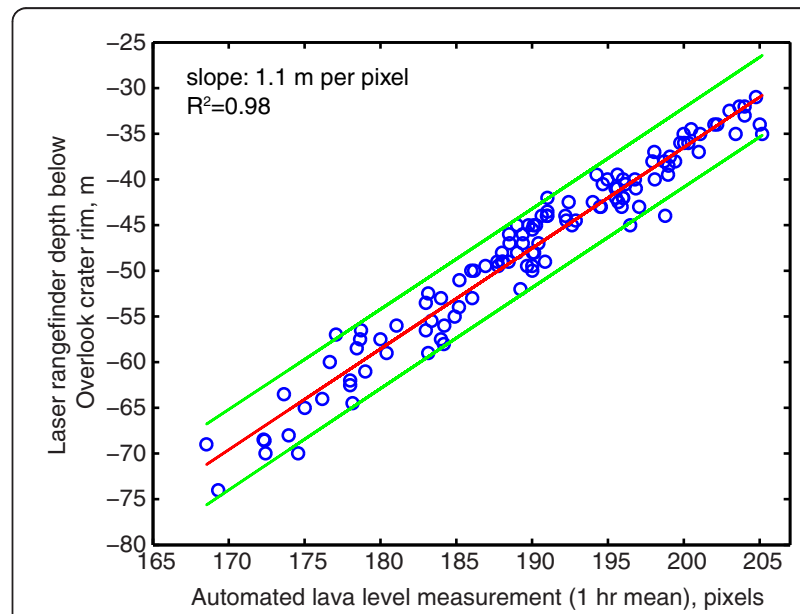

Fig. 4 Scatter plot of automated lava-level measurement, measured in pixels from the bottom of the image (Fig. 2f), with the lava lake level as measured by a laser rangefinder. Data collected between January and May 2014. The hourly mean of the automated measurement is used here. The laser rangefinder results show the depth of the lava lake below the Overlook crater rim, which was at about 1023 m elevation above sea level in 2014. The red line shows the best linear fit, while the green lines represent \pm 2 times the standard error 
multiple monitoring datastreams, such as ground tilt, gas emission rates and earthquake frequency. In addition to the script that analyzes images, another script runs every 15 min and produces an online "dashboard" update of lava level data (Fig. 5). Sporadic laser rangefinder measurements, described above, provide an empirical conversion between image pixels and lava level in meters. In the dashboard plots, the automated lava-level results are converted to meters and smoothed (using a 5 point moving average), and shown along with laser rangefinder measurements. The time series show the past week and past month of lava level, along with ground tilt for the same periods. The most recent thermal camera image is also shown, along with a calibrated scale bar showing depth in meters below the Overlook crater rim, for the user to make a judgment of depth based on the current image. Although the lava level plot data are updated once an hour, the 15 min refresh rate on the dashboard display provides a near-realtime view of the lake with the calibrated scale bar.

\section{Discussion}

Lava-level tracking is an important part of monitoring Kilauea's activity. Patrick et al. $(2014,2015)$ show examples during 2011 when three episodes of rising lava level (and summit inflation) each culminated in eruptive events on the East Rift Zone. This suggests that lava level, in addition to surface deformation and seismic activity, may be another tool for judging magma pressurization and eruptive potential. During May 2014, relatively high lava levels ( $\sim 30 \mathrm{~m}$ below the Overlook crater rim, which is at $1023 \mathrm{~m}$ elevation above sea level, so equivalent to roughly $990 \mathrm{~m}$ elevation) were sustained for several weeks, as the summit inflated (Fig. 6). These parameters indicated the magmatic system of Kilauea was pressurizing, which sometimes precedes intrusions or eruptive events on the East Rift Zone (Poland et al. 2008; Orr et al. 2015). A remarkable correlation between lava level and summit ground tilt also exists (Fig. 6), demonstrating that the summit lava level acts as an effective "pressure gauge" of
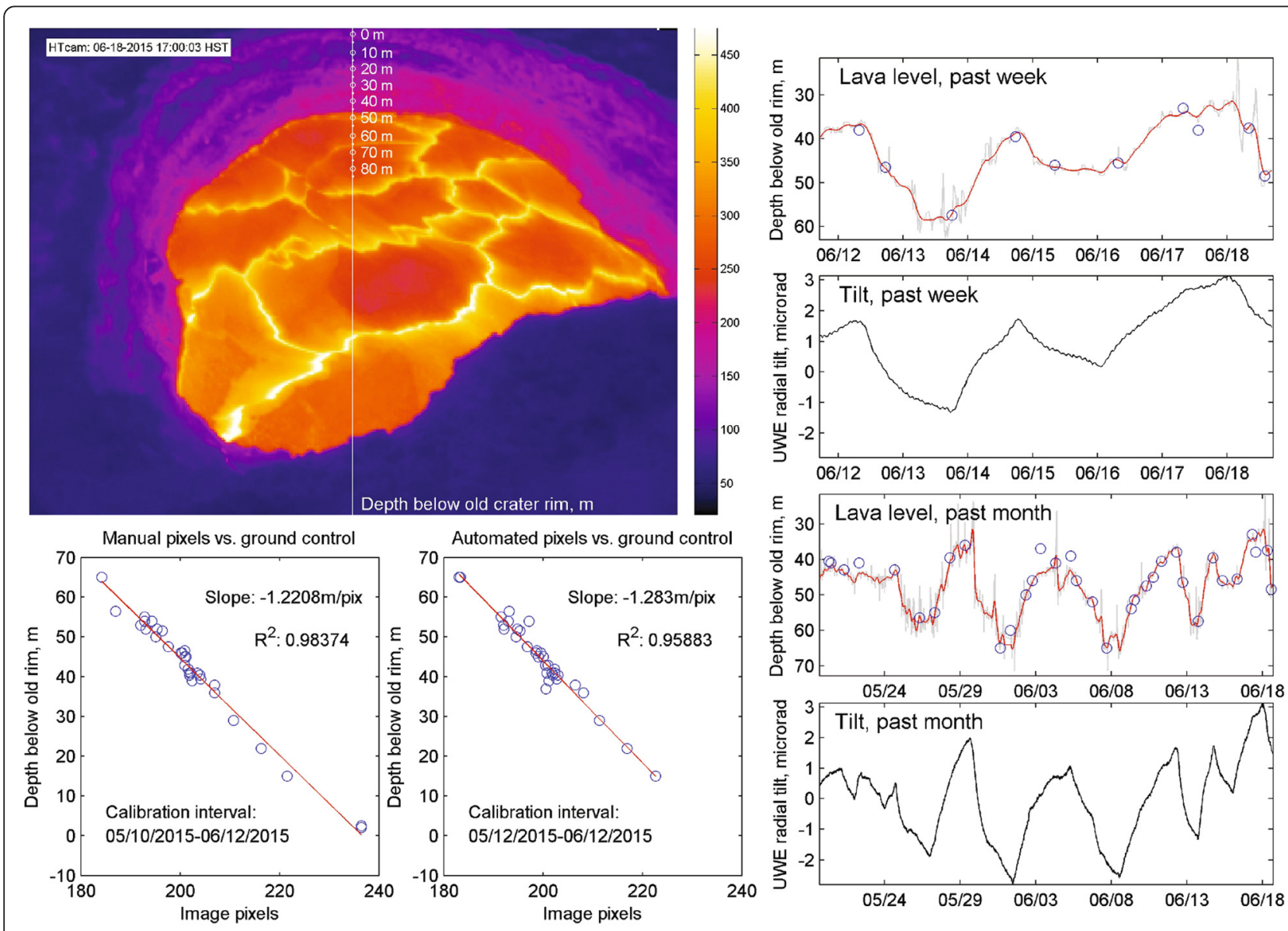

Fig. 5 Online "dashboard" display of recent lava level results, combining the automated tracking and laser rangefinder calibration measurements. In the lava-level plots on the right, the light gray line is the raw lava level measurement, and the red line is the smoothed version. Blue circles are laser rangefinder points. The conversion between image pixel measurements of lake depth and actual depth in meters below the rim of the Overlook crater is based on the manual pixel correlation shown at the lower left plot. This dashboard display is automatically updated every fifteen minutes 


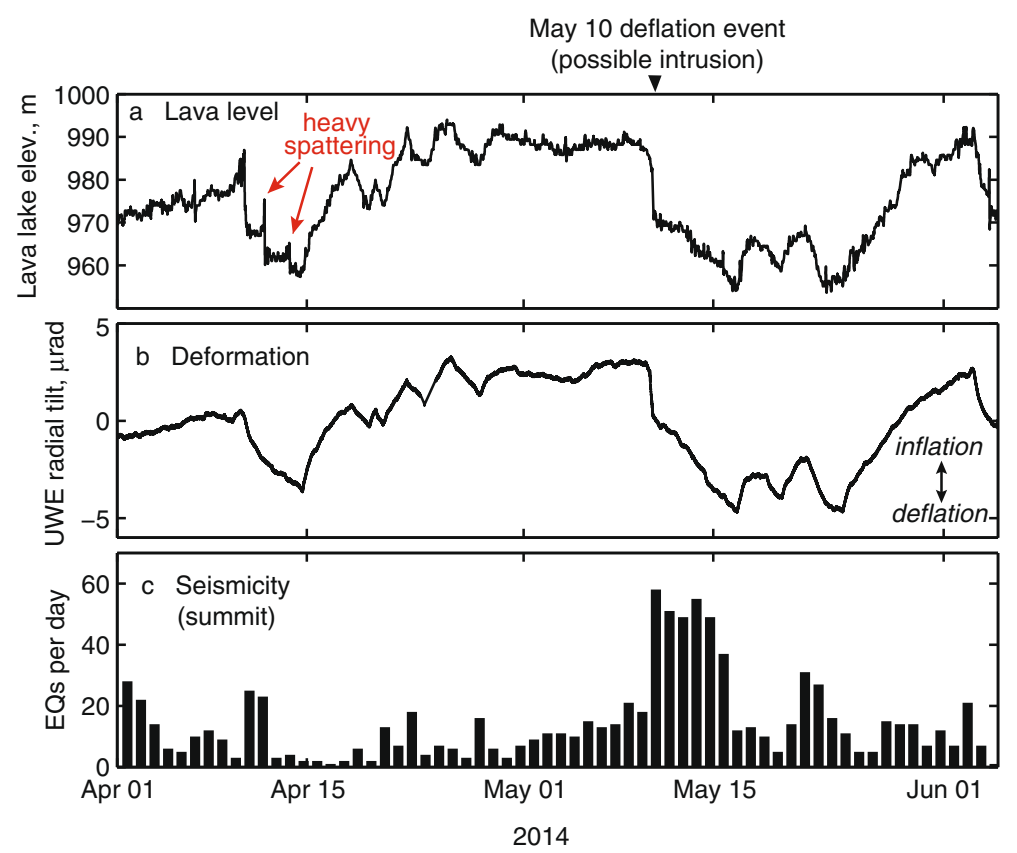

Fig. 6 Multiparameter plot of lava level and ground tilt fluctuations at Killauea in mid-2014. a. Automated result for lava level (hourly average), converted to absolute elevation using the linear regression shown in Fig. 4. b. Summit ground tilt from the UWE tiltmeter, approximately 2 km from the lava lake in Halema'uma'u. Increasing and decreasing values imply inflation and deflation, respectively. c. Number of located earthquakes per day in the upper East Rift Zone. The strong correlation between lava level and ground tilt suggests the lake acts as an effective "pressure gauge" of the summit magma reservoir. Elevated lava levels (and tilt) were present during late April and early May, culminating in an abrupt drop in lava level and summit deflation on May 10, which preceded elevated earthquake activity for the next several days. Preliminary interpretation suggests that a small intrusion occurred in response to the elevated summit pressure, dropping the level of the lava in the lake. Episodes of intense spattering are visible as transient spikes in lava level, followed by rapid drops (a real drop in lava lake level due to gas release)

Kìlauea's summit magma reservoir (Patrick et al. 2015). This correlation confirms previous studies that have suggested such a relationship with earlier data (Tilling 1987; Denlinger 1997). Superimposed on the broad-scale trends of lake level and deformation are small-scale fluctuations that reflect "DI events" (a characteristic cycle of deflation followed by inflation) (Cervelli and Miklius 2003; Anderson et al. 2015). The high lava level in early May 2014 dropped abruptly approximately $20 \mathrm{~m}$ on May 10, as the summit rapidly deflated. This change of lake level and deformation preceded a week of elevated earthquake activity around the summit. Although no new eruptive vents opened, as had occurred in 2011 following elevated lava levels, preliminary interpretation suggests that a small intrusion at the summit occurred. The intrusion depressurized the summit magma reservoir, producing a drop in lava level. Throughout this time period, thermal images and automated lava level results kept HVO staff informed of current activity levels.

Not all lava level changes, however, are due to pressure fluctuations. In general, short-term changes (e.g. seconds to hours) are normally attributable to shallow gas-related processes, such as rockfall-triggered spattering (Orr et al. 2013) and "gas pistoning" (Swanson et al. 1979; Patrick et al. 2011, 2014, 2016; Nadeau et al. 2015). Two episodes of intense spattering occurred on April 10-11, 2014, during deflation and lava level drop (Fig. 6), and at least one of these episodes was related to a small rockfall into the lake. The spattering episodes are visible as spikes in lava level, followed by a rapid drop in lava level. The spike itself is an artifact, in which spattering along the north margin of the lake causes the algorithm to incorrectly detect a rise in the entire lake. However, the drop in lava level following the spike is real, and presumably due to release of a large volume of gas during the intense spattering phase (Patrick et al. 2016). This characteristic lava level signal - a spike followed by sharp drop - is diagnostic of intense spattering episodes, which are often triggered by small rockfalls into the lake.

\section{Conclusions}

The automated measurement of lava level is an effective tool for operational monitoring at HVO, allowing $\mathrm{HVO}$ staff to quickly assess recent changes in lava level and compare these changes with other datasets. This approach uses several arbitrary thresholds (e.g. $300{ }^{\circ} \mathrm{C}$ for the maximum temperature composite image, Fig. 2c) based on rough trial and error, and these thresholds could be improved with a more rigorous optimization. We expect that other segmentation approaches could 
also be effective at isolating the lava lake from its surroundings for level measurement. Furthermore, this image processing routine could likely be performed with free, open-source software such as Python. Future work tracking the lava level with thermal imagery could include an additional camera and development of an automated photogrammetric routine to create a surface model of the Overlook crater, thereby measuring not only lava level but also changing vent crater geometry.

As webcams, thermal cameras and other types of imaging systems increase in number at volcano observatories worldwide (Spampinato et al. 2011; Kern et al. 2014), the need for automated analyses using the incoming images will likewise become greater. Automated image analysis not only provides a more efficient use of human resources, but also allows a continuous, uninterrupted watch on activity levels.

\section{Competing interests}

The authors declare that they have no competing interests.

\section{Authors' contributions}

MP wrote the code and the manuscript. DA and TO collected laser rangefinder data and made observations of lava lake activity. All authors read and approved the final manuscript.

\section{Acknowledgements}

HVO staff members Kevan Kamibayashi, Loren Antolik and Lopaka Lee were vital to installing and maintaining the camera and acquisition system. We thank C. Kern, J. Major and an anonymous reviewer for comments which improved the manuscript. Funding for the thermal cameras was provided by the American Reinvestment and Recovery Act. Any use of trade, firm, or product names is for descriptive purposes only and does not imply endorsement by the U.S. Government.

Received: 8 July 2015 Accepted: 8 March 2016

Published online: 16 March 2016

\section{References}

Anderson K, Poland M, Johnson J, Miklius A Episodic deflation-inflation events at Kilauea Volcano and implications for the shallow magma system. In: Carey R, Poland M, Cayol V, Weis D (eds) Hawaiian Volcanism: From Source to Surface: Hoboken, New Jersey, Wiley, American Geophysical Union Geophysical Monograph 2015;208:229-250

Cervelli PF, Miklius A The shallow magmatic system of Kilauea Volcano. In: Heliker C, Swanson DA, Takahashi TJ (eds) The Pu'u 'Ō'ō-Kupaianaha eruption of Kilauea Volcano, Hawai'i: The first 20 years: U.S. Geological Survey Professional Paper 2003;1676:149-163

Cervelli DP, Cervelli PF, Miklius A, Krug R, Lisowski M. VALVE: Volcano Analysis and Visualization Environment. Eos, Transactions of the American Geophysical Union, v. 83, Fall Meeting Supplement, Abstract U52A-01. 2002.

Denlinger RP. A dynamic balance between magma supply and eruption rate at Kilauea volcano, Hawaii. J Geophys Res. 1997;102:18091-100.

Gonzalez RC, Woods RE, Eddins SL. Digital image processing using Matlab. Upper Saddle River, NJ: Pearson Prentice Hall; 2004.

Kern C, Sutton J, Elias T, Lee L, Kamibayashi K, Antolik L, Werner C. An automated SO2 camera system for continuous, real-time monitoring of gas emissions from Kilauea Volcano's summit Overlook crater. J Volcanol Geotherm Res. 2014;300:81-94.

Nadeau PA, Werner CA, Waite GP, Carn SA, Brewer ID, Elias T, Sutton AJ, Kern C Using SO2 camera imagery to examine degassing and gas accumulation at Kilauea volcano, May 2010. J Volcanol Geotherm Res. 2015;300:70-80. doi:10. 1016/j.jvolgeores.2014.12.005.

Orr TR, Thelen WA, Patrick MR, Swanson DA, Wilson DC. Explosive eruptions triggered by rockfalls at Kilauea Volcano, Hawai'i. Geology. 2013;41:207-10.
Orr T, Poland MP, Patrick MR, Thelen WA, Sutton AJ, Elias T, Thornber CR, Parcheta C, Wooten KM Kilauea's 5-9 March 2011 Kamoamoa fissure eruption and its relation to $30+$ years of activity from Pu'u 'Ō'o. In: Carey R, Poland M, Cayol V, Weis D (eds) Hawaiian Volcanism: From Source to Surface: Hoboken, New Jersey, Wiley, American Geophysical Union Geophysical Monograph 2015;208:393-420

Patrick MR, Kauahikaua JP, Antolik L. MATLAB tools for improved characterization and quantification of volcanic incandescence in webcam imagery: applications at Kilauea Volcano, Hawaii. U.S. Geological Survey Techniques and Methods 13-A1. 2010.

Patrick MR, Wilson D, Fee D, Orr T, Swanson D. Shallow degassing events as a trigger for very-long-period seismicity at Kilauea Volcano, Hawai'í. Bull Volcanol. 2011;73:1179-86.

Patrick MR, Orr T, Sutton AJ, Elias T, Swanson D The first five years of Kilauea's summit eruption in Halema'uma'u Crater. US Geological Survey Fact Sheet 2013;2013-3116. http://dx.doi.org/10.3133/fs20133116

Patrick MR, Orr TR, Antolik L, Lee R, Kamibayashi K. Continuous monitoring of Hawaiian volcanoes using thermal cameras. J Appl Volcanol. 2014;3:1.

Patrick MR, Anderson KR, Poland MP, Orr T, Swanson D. Lava lake level as a gauge of magma reservoir pressure and eruptive hazard. Geology. 2015;43:831-4.

Patrick MR, Orr T, Sutton AJ, Lev E, Thelen W, Fee D. Shallowly driven fluctuations in lava lake outgassing (gas pistoning), Kilauea Volcano. Earth Planet Sci Lett. 2016;433:326-38.

Poland MP, Miklius A, Orr T, Sutton AJ, Thornber C, Wilson D. New episodes of volcanism at Killauea Volcano, Hawaii. Eos Transactions AGU. 2008;89:37-8.

Rowland SK, Munro DC. The 1919-1920 eruption of Mauna Iki, Kilauea: chronology, geologic mapping, and magma transport mechanisms. Bull Volcanol. 1993;55:190-203.

Spampinato L, Calvari S, Oppenheimer C, Boschi E. Volcano surveillance using thermal cameras. Earth-Sci Rev. 2011;106:63-91.

Swanson DA, Duffield WA, Jackson DB, Peterson DW. Chronological narrative of the 1969-71 Mauna Ulu eruption of Kilauea volcano, Hawaii. U.S. Geological Survey Professional Paper 1056. 1979.

Tilling Rl. Fluctuations in surface height of active lava lakes during 1972-1974 Mauna Ulu eruption, Kilauea Volcano, Hawaii. J Geophys Res. 1987;92:13721-30.

Wilson D, Elias T, Orr T, Patrick M, Sutton AJ, Swanson D. Small explosion from new vent at Kilauea's summit. Eos Transactions AGU. 2008;89(22):203. doi:10.1029/2008EO220003.

\section{Submit your manuscript to a SpringerOpen ${ }^{\odot}$ journal and benefit from:}

- Convenient online submission

- Rigorous peer review

- Immediate publication on acceptance

- Open access: articles freely available online

- High visibility within the field

- Retaining the copyright to your article

Submit your next manuscript at $\boldsymbol{s p r i n g e r o p e n . c o m ~}$ 